\title{
"Volatility dynamics and the risk-return relationship in South Africa: A GARCH approach"
}

\begin{tabular}{|c|c|}
\hline \multirow{3}{*}{ AUTHORS } & Nitesha Dwarika (iD) \\
\hline & Peter Moores-Pitt (iD) \\
\hline & Retius Chifurira (iD) \\
\hline ARTICLE INFO & $\begin{array}{l}\text { Nitesha Dwarika, Peter Moores-Pitt and Retius Chifurira (2021). Volatility } \\
\text { dynamics and the risk-return relationship in South Africa: A GARCH approach. } \\
\text { Investment Management and Financial Innovations, 18(2), 106-117. } \\
\text { doi:10.21511/imfi.18(2).2021.09 }\end{array}$ \\
\hline DOI & http://dx.doi.org/10.21511/imfi.18(2).2021.09 \\
\hline RELEASED ON & Friday, 07 May 2021 \\
\hline RECEIVED ON & Wednesday, 06 January 2021 \\
\hline \multirow[t]{2}{*}{ ACCEPTED ON } & Monday, 05 April 2021 \\
\hline & $(\mathrm{sc}) \mathrm{EY}$ \\
\hline LICENSE & $\begin{array}{l}\text { This work is licensed under a Creative Commons Attribution } 4.0 \text { International } \\
\text { License }\end{array}$ \\
\hline JOURNAL & "Investment Management and Financial Innovations" \\
\hline ISSN PRINT & $1810-4967$ \\
\hline ISSN ONLINE & $1812-9358$ \\
\hline PUBLISHER & LLC “Consulting Publishing Company "Business Perspectives" \\
\hline FOUNDER & LLC "Consulting Publishing Company "Business Perspectives" \\
\hline
\end{tabular}

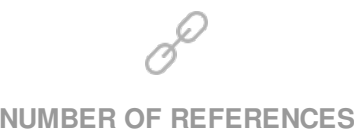

18

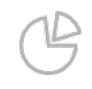

NUMBER OF FIGURES

0

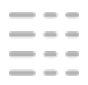

NUMBER OF TABLES

9

(C) The author(s) 2021. This publication is an open access article. 


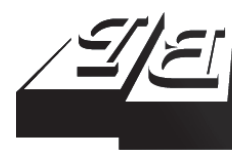

\section{BUSINESS PERSPECTIVES}

(O)

LLC "CPC "Business Perspectives" Hryhorii Skovoroda lane, 10, Sumy, 40022, Ukraine www.businessperspectives.org
Received on: $6^{\text {th }}$ of January, 2021 Accepted on: $5^{\text {th }}$ of April, 2021 Published on: $7^{\text {th }}$ of May, 2021

(c) Nitesha Dwarika, Peter Moores-Pitt, Retius Chifurira, 2021

Nitesha Dwarika, Master of Commerce (MCom) Finance, University of KwaZulu-Natal, South Africa.

Peter Moores-Pitt, Doctor of Philosophy (Ph.D.) Finance, University of KwaZulu-Natal, South Africa.

Retius Chifurira, Doctor of Philosophy (Ph.D.) Statistics, University of KwaZulu-Natal, South Africa. (Corresponding author)

Nitesha Dwarika (South Africa), Peter Moores-Pitt (South Africa),

Retius Chifurira (South Africa)

\title{
VOLATILITY DYNAMICS AND THE RISK-RETURN RELATIONSHIP IN SOUTH AFRICA: A GARCH APPROACH
}

\begin{abstract}
This study is aimed at investigating the volatility dynamics and the risk-return relationship in the South African market, analyzing the FTSE/JSE All Share Index returns for an updated sample period of 2009-2019. The study employed several GARCH type models with different probability distributions governing the model's innovations. Results have revealed strong persistent levels of volatility and a positive risk-return relationship in the South African market. Given the elaborate use of the GARCH approach of risk estimation in the existing finance literature, this study highlighted several weaknesses of the model. A noteworthy property of the GARCH approach was that the innovation distributions did not affect parameter estimation. Analyzing the GARCH type models, this theory was supported by the majority of the GARCH test results with respect to the volatility dynamics. On the contrary, it was strongly unsupported by the risk-return relationship. More specifically, it was found that while the innovations of the EGARCH $(1,1)$ model could account for the volatile nature of financial data, asymmetry remained uncaptured. As a result, misestimating of risks occurred, which could lead to inaccurate results. This study highlighted the significance of the innovation distribution of choice and recommended the exploration of different nonnormal innovation distributions to aid with capturing the asymmetry.
\end{abstract}

\section{Keywords}

JEL Classification

\section{INTRODUCTION}

The condition of a country's financial system is a key indicator of a country's stability. It forms the foundation for progression in terms of sustainable economic growth, development and job creation. While contributing to the overall stability of a country, it can also affect local and foreign investment decisions. In this context, the state of the financial market can either attract or repel investors, affecting the growth of the nation. By understanding the status of a financial market, investors' decision-making process and investment strategies can be assisted and structured accordingly. That is, it must be estimated what level of risk they should take concerning an investment in venture to optimize their chance to earn a superior return.

The volatile nature of a market causes key indicators of forecasting, i.e., risks and returns, to be difficult to apply. Moreover, it becomes rather unreliable if inadequate models are used. Thus, forecasting risk and price movements remains a fundamental problem for any financial market. The Generalised Autoregressive Conditional Heteroscedasticity (GARCH) models are a preferred method to quantify the risk (Feng \& Shi, 2017). An underlying assumption for GARCH modelling by Engle (1982), is that asset returns follow a normal distri- 
bution. The normality assumption of asset returns is considered unrealistic, given the empirical nature of returns which is asymmetric and volatile. Particularly for emerging markets, i.e., those of South Africa that show unique market return characteristics, are considered to have heavy tails and high levels of volatility, as pointed out by Adu et al. (2015).

To address these factors, there has been some extensions added to the standard GARCH model, as well as different nonnormal innovation distributions introduced to assist with capturing the asymmetry. The problem statement is that if data properties violate the unrealistic assumptions of the GARCH approach, then the parameter estimates are going to be misleading. This is viewed as problematic due to the GARCH approach being accepted as a reliable method in risk estimation and could result in inaccurate decisions that lead to financial losses.

As such, this article investigates the South African market with the goal of understanding the conditions and price movements of the market. By applying the more advanced extensions to the GARCH model, it is likely to improve forecast accuracy. It is expected that the extensions of the standard GARCH model will determine evidence of asymmetry and significant levels of volatility, contributing to a greater understanding of the market. In turn, this will highlight its suitability for investors with a less than typical aversion to risk in order to a realize upside potential.

\section{LITERATURE REVIEW}

Understanding the dynamics in a market can assist investors in strategizing their investment ventures to optimise their probability of realising a superior return. Drawn from Yu et al. (2019), volatility is defined as a strong persistence of risk and is asymmetric in nature. Asymmetric volatility refers to the tendency for volatility to increase more in response to changes of the same absolute magnitude in negative returns than for changes in positive returns, or vice versa. This phenomenon is documented as an empirical regularity in most financial markets, and has been systematically proven over time as sufficed by $\mathrm{Yu}$ et al. (2019), Khan et al. (2016), Mandimika \& Chinzara (2012). The GARCH models often treat the leverage effect similarly as the asymmetric volatility (Mandimika \& Chinzara, 2012).

According to Khan et al. (2016), the GARCH approach can account several market characteristics such as volatility clustering and the asymmetric effects - asymmetric volatility and the leverage effect. The authors employed the three most common GARCH models - GARCH $(1,1)$, EGARCH and GARCH-M over the sample period from June 1998 to June 2012. Monthly returns were obtained from the Karachi Stock Exchange 100 Index and twenty-three sectors of the Pakistani equity market. The study aimed to analyze volatility dynam- ics on an aggregate market and disaggregated sectorial level where the sectors were selected based on their accessibility.

The GARCH $(1,1)$ can identify the clustering nature of volatility found in price data by capturing its persistence. Khan et al. (2016) stated that the GARCH $(1,1)$ model revealed persistent volatility but at different levels across the sectors. To capture further market characteristics, there have been used several extensions of the standard GARCH model. The first of these is the EGARCH model, modified to capture the asymmetric effects. Khan et al., (2016) found the presence of the weak asymmetric effects by EGARCH, on both an aggregate and disaggregate levels.

The GARCH-M model is used for the pricing of risk, which revealed whether returns depend on the risks. Khan et al. (2016) found that risk was priced in the Pakistani market and that a positive risk-return relationship exists there. However, Mandimika \& Chinzara (2012) stated that the GARCH-M model has its limitations as it can't capture asymmetry. Jin (2017) highlighted that the GARCH approach is prone to model misspecification as it has underlying assumptions and constraints due to being a parametric model. Furthermore, Feng \& Shi (2017) found that risk remained uncaptured by the GARCH model's innovations. 
Khan et al. (2016) recommended to analyze economic fundamentals as these were driving forces of asymmetric volatility. Park et al. (2017) applied the DCC-MGARCH model to the daily data sets of the Korean market for the sample period from 2004 to 2013 . The study analyzed the variables of KOSPI200 returns, an implied volatility measure and four macroeconomic variables - risk-free rates, term spreads, credit spreads and exchange rates. A sign and size bias test and joint effect (JE) test showed that the standard GARCH model inadequately captures risks, which confirmed the symmetric nature of the GARCH model. The final findings by Park et al. (2017), revealed mixed results where the return in relation to the macroeconomic factors varied based on the type of regression analysis and specifications.

In a BRICS study, Adu et al. (2015) used the ARMAEGARCH-M over the sample period from January 1995 to May 2014 to analyse the MSCI index. The daily data sets of the largest stock markets in the respective countries were of primary focus. The market return characteristics of an emerging market were confirmed to have heavy tails due to higher levels of volatility. The leverage effect was detected at all the emerging markets except for the South African one, and concluded that there is no risk-return relationship in the South African market.

Mangani (2008) also found no risk-return relationship except for the vague evidences of asymmetric effects in the South African market. The Johannesburg Stock Exchange (JSE) was investigated as it was the largest stock market in South African market at the time. The study employed the GARCH $(1,1)$, EGARCH and DGARCH models to the weekly ALSI returns for the sample period from February 1973 to April 2002. Mangani (2008) concluded that the GARCH $(1,1)$ model was the most effective one. The study found that the innovations demonstrated random behaviour by the Brock, Dechert and Scheinkman (BDS) randomness test. In turn, this suggested that nonlinearities remained uncaptured within the innovations of the model.

Following Mangani (2008), Mandimika \& Chinzara (2012) applied the normal, student-t and Generalised Error Distribution (GED) in combination with the EGARCH-M, TARCH-M and
GARCH-M models to improve the results of their study. The analysis used the JSE daily data for the sample period from 1995 to 2009. Results revealed strong persistent volatility over time and significant evidence of the asymmetric effects. The study concluded the TARCH-M to be the most robust model and GED to be the optimal innovation distribution from the diagnostic testing of information criteria. It was recommended to take into account the higher moment properties upon condition of inconclusive results. This can be addressed by the employment of different innovation distributions, in contrast to Spierdijk (2016), who stated that the innovation distributions did not affect parameter estimation.

Ilupeju (2016) applied the APARCH model for analysis of the daily data set of JSE ALSI returns, in addition to the GARCH models employed by Mandimika \& Chinzara (2012), over the sample period from May 20, 2005 to May 31, 2016. The study used the Skewed-Student-t distribution, Pearson Type IV distribution (PIVD), Generalised Pareto distribution (GPD), Generalised Extreme Value distribution (GEVD) and stable distribution. Sign and size bias tests revealed the presence of volatility clustering and the leverage effect in the South African market. As an optimal model, the study identified the APARCH model with PIVD and GPD for the short-run and the stable innovation distribution for the long-run. The randomness tests, i.e., BDS, Bartels rank and Cox-Stuart, were applied to the APARCH model. As a result, nonlinearities remained uncaptured, in line with Mangani (2008).

From a chronological review of the South African literature, it was noted that more significant evidence was found regarding the asymmetric effects. Mandimika \& Chinzara (2012) further noted that while using different innovation distributions, the results could be improved by accounting for asymmetry that the model itself could not fully capture. With this in mind, this study employed the GARCH approach with different innovation distributions to investigate the market conditions of the South African market to provide useful information for the market participants. Following the documented South African studies, the largest stock exchange, the JSE was investigated where the daily ALSI returns were analyzed. 


\section{METHODOLOGY}

This study was performed by analyzing different types of GARCH models and innovation distributions to determine if asymmetry had been adequately captured. The optimal GARCH model was selected and the model's innovations were specifically investigated to show whether the risk was fully captured.

\subsection{Dataset}

Following Mandimika \& Chinzara (2012), the choice of data and variables was as follows. The secondary daily price data of the FTSE/JSE All Share Index (ALSI) was obtained from the IRESS database for the sample period from October 15, 2009 to - October 15, 2019. Daily data were analyzed as high-frequency data provided a more accurate estimation of the variables. The timeframe of this study was ten years. The sample included only listed companies, so newly listed and delisted companies were excluded. The choice of this period aimed to limit the potential effects of structural breaks in the analysis. While it could have been extended, it would become more susceptible to the influences of exogenous economic shocks, which, in that context, affected the accuracy of the GARCH test results (Jin, 2017).

The daily ALSI price data was converted to ALSI market returns by the $\log$ transformation of Equation 1:

$$
R_{m}=\ln \left(\frac{P_{t}}{P_{t-1}}\right)
$$

where $R_{m}$ denoted market returns and $P_{t}$ represented the share price for the current day $t$ and $P_{t-1}$ was the share price for the previous day $t-1$, where $t=1, \ldots, 2499$. This step ensured the stationarity requirement for GARCH modelling and is standard practice in finance literature (Khan et al., 2016). Thereafter, the calculation of excess returns was made by Equation 2:

$$
r_{t}=R_{m}-R_{f}
$$

where $r_{t}$ denoted the market risk premium, equal to the difference between the market return $R_{m}$ and the risk-free rate $R_{f}$. The annual risk-free rate was obtained from the South African Reserve Bank (SARB) and converted to a daily value from Equation 3 by Brooks (2014):

$$
\text { Daily } R_{f}=\left(1+\text { yearly } R_{f}\right)^{\left(\frac{1}{365}\right)} .
$$

The South African Treasury Bill was the proxy for the risk-free rate based on accessibility and availability, in line with Mandimika \& Chinzara (2012).

To motivate the application of the GARCH approach, the ALSI returns underwent heteroscedasticity tests, following Khan et al. (2016). To investigate if the ALSI data were heteroscedastic, the Ljung-Box $\left(\mathrm{LB}^{2}\right)$ and Autoregressive Conditional Heteroscedastic Lagrange Multiplier (ARCH-LM) tests were employed.

\section{2. $\operatorname{GARCH}(1,1)$}

Bollerslev (1986) introduced the GARCH model as an extension of the ARCH model, where the current conditional variance was a function of past volatility as well as the innovation terms.

$$
\sigma_{t}^{2}=\alpha_{0}+\sum_{i=1}^{q} \alpha_{i} u_{t-1}^{2}+\sum_{j=1}^{p} \beta_{j} \sigma_{t-j}^{2}
$$

As shown by Equation 4, the conditional variance $\sigma_{t}^{2}$ was time-varying and dependent on the past lagged innovation terms squared $u_{t-1}^{2}$. Volatility clustering described the clustering nature of volatility, heavy tails and excess kurtosis as measured by their persistence (Adu et al., 2015). The ARCH effect $\alpha_{1}$ represented the persistence of risk over a short period while the GARCH effect $\beta_{1}$ covered the long-term.

Khan et al. (2016) stated that the conditional variance is subject to change, but the unconditional variance of the innovation terms is constant. Therefore, the assumption of stationarity for the innovation terms only holds when $\sum \alpha_{i}+\sum_{j} \beta_{j}<1$. If this constraint is satisfied, thle assuniption of stationarity is valid and the long-run mean variance converges to unconditional variance given by Equation 5:

$$
\sigma_{t}^{2}=\operatorname{var}\left(u_{t}\right)=\frac{\alpha_{0}}{1-\left(\sum_{i=1}^{q} \alpha_{i}+\sum_{j=1}^{p} \beta_{j}\right)} .
$$


As shown by From Equation 5, if

$$
\sum_{i=1}^{q} \alpha_{i}+\sum_{j=1}^{p} \beta_{j}<1 \text {, the unconditional variance }
$$

for the innovation terms was undefined and nonstationary.

If $\sum_{i=1}^{q} \alpha_{i}+\sum_{j=1}^{p} \beta_{j}=1$, the unconditional variance

was nonstationary and the above convergence would not occur. However,

if $\sum_{i=1}^{q} \alpha_{i}+\sum_{j=1}^{p} \beta_{j}>1$, the forecast of conditional

variance would increase to infinity as the sample period increases.

To confirm the GARCH models' inadequacy to capture risks, the model underwent an asymmetry test, following Park et al. (2017). Essentially, if the JE test statistic is significant, it can be concluded that asymmetry was present and the GARCH model inadequately captured the asymmetric nature of the ALSI returns.

\subsection{GJR-GARCH $(1,1)$}

Glosten et al. (1993) extended the GARCH model with the addition of the term $\gamma u_{t-1}^{2} I_{t-1}$.

$$
\sigma_{t}^{2}=\alpha_{0}+\sum_{i=1}^{q} \alpha_{i} u_{t-1}^{2}+\sum_{j=1}^{p} \beta_{j} \sigma_{t-j}^{2}+\gamma u_{t-1}^{2} I_{t-1}
$$

As shown by Equation 6.1, $\alpha_{0}$ denoted a constant term and $\alpha_{1}$ denoted the parameter of the squared lagged innovation term $u_{t-1}^{2}$. The parameter $\alpha_{1}$ and $\beta_{j}$ followed the standard GARCH model and the asymmetry parameter of interest $\gamma$ captured the asymmetric effects.

$$
I_{t-1}=\left\{\begin{array}{l}
1, \text { if } u_{t-1}<1 \\
0, \text { otherwise }
\end{array}\right.
$$

As shown by Equation 6.1, the interaction variable $I_{t-1}$ given by Equation 6.2, distinguishes the effects of positive and negative volatility.

Drawn from Mandimika and Chinzara (2012), when $\gamma \neq 0$, the asymmetric volatility is present, where positive and negative volatility shocks or news impacted volatility differently. The volatility shock or type of news was represented by the sign of $\alpha_{1}$. For a positive sign of $\alpha_{1}$, good news had a greater impact on volatility than bad news of the same magnitude at the market. If $\gamma>0$, this indicated the presence of both asymmetric effects, but if $\gamma<0$, the presence of asymmetric volatility, but the absence of the leverage effect, is indicated.

\section{4. $\operatorname{EGARCH}(1,1)$}

The exponential GARCH model by Nelson (1991), was specially designed to capture asymmetric effects without being subject to any nonnegativity constraints, in contrast to all other GARCH models.

$$
\begin{aligned}
& \ln \left(\sigma_{t}^{2}\right)=\alpha_{0}+\sum_{i=1}^{q} \alpha_{i}\left[\left|z_{t-1}\right|-\mathrm{E}\left|z_{t}\right|\right]+ \\
& +\sum_{j=1}^{p} \beta_{j}\left(\sigma_{t_{t-j}}^{2}\right)+\gamma z_{t-1} .
\end{aligned}
$$

As shown by Equation 7, the conditional variance was able to respond in a nonlinear manner to positive and negative returns by the magnitude of the innovation $\alpha_{1}\left[\left|z_{t-1}\right|-\mathrm{E}\left|z_{t}\right|\right]$ and the sign effect $\gamma z_{t-1}$. The interpretation of the asymmetry parameter ã followed the GJR model (Ilupeju, 2016).

\section{5. $\operatorname{APARCH}(1,1)$}

Following the asymmetric GARCH models, Ding et al. (1993) used the asymmetric power ARCH model.

$$
\sigma_{t}^{\delta}=\alpha_{0}+\sum_{i=1}^{p} \alpha_{i}\left(\left|e_{t-i}\right|-\gamma_{i} e_{t-i}\right)^{\delta}+\sum_{j=1}^{q} \beta_{j} \sigma_{t-j}^{\delta} .
$$

As shown by Equation 8, $\gamma$ showed the asymmetric effects where a positive value meant that negative volatility shocks have a greater impact than positive. The parameter $\delta$ shown as the exponent enhances the model to the extent that it can take on a number of ARCH and GARCH models.

To conclude the investigation of volatility dynamics, the optimal fitting GARCH model and innovation distribution were selected by information criteria. This selection was determined by the smallest values of the Akaike Information Criterion (AIC) and the Bayesian Information 
Criterion (BIC), following Khan et al. (2016). The standardised innovations were investigated, to determine if risk remained uncaptured, employing a number of preliminary tests, following Mangani (2008), Mandimika \& Chinzara (2012). The normality tests used were Shapiro-Wilk (SW), Jarque-Bera (JB) and Anderson-Darling (AD), as well as the heteroscedasticity tests, the $\mathrm{LB}^{2}$ and ARCH-LM. Finally, the independent and identically distributed (IID) tests were the BDS, Bartels rank and Cox-Stuart.

\subsection{GARCH $(1,1)-M$}

Engle et al. (1987) introduced the ARCH-in-mean model, which was extended to the GARCH-inmean model since the GARCH models became relatively more popular. The 'in-mean' is in reference to the conditional mean, which contains the conditional variance and the risk premium parameter of which the latter is used to determine the risk-return relationship.

$$
y_{t}=\mu+\sum_{j=1}^{p} \delta_{j} \sigma_{t-j}^{2}+u_{t}, u_{t} \sim N(0,1) .
$$

Equation 9 showed the ARCH-M specification, the risk premium $\delta_{j}$, following standard literature. The conditional variance $\sigma^{2}$ of the GARCH-M and EGARCH-M model followed Equation 4 and Equation 7, respectively.

It should be noted that for the preliminary tests and the GARCH approach, the results were drawn from the $p$-value, following the majority of studies reviewed such as Mangani (2008), Mandimika \& Chinzara (2012), Adu et al. (2015) and Ilupeju (2016). If the $p$-value was less than the standard $5 \%$ level of significance, the null hypothesis can be rejected; thus, the alternative hypothesis was concluded. If the $p$-value was greater than the standard $5 \%$ level of significance, the null hypothesis was not rejected and the null hypothesis was concluded.

\section{RESULTS}

\subsection{Preliminary tests}

Following standard literature, the ALSI index level data was differenced to log form before data exploration, to ensure stationarity and avoid a spurious regression. Table 1 showed the basic descriptive statistics of the ALSI returns.

According to Table 1, the ALSI excess returns have an average value of 0.000 translating to a corresponding rate of the return, which was indicative of a nonprofitable trading strategy in the South African market. The negative skew value of -0.167 described a distribution that tended to the left. The positive value of excess kurtosis of 1.277 meant that the ALSI returns followed a leptokurtic distribution, which is a peaked distribution with heavy tails. Thus, the results from the basic descriptive statistics showed that the ALSI returns followed an asymmetric distribution. Table 2 showed the test results for heteroscedasticity.

According to Table 2, since the $p$-values of both the $\mathrm{LB}^{2}$ and $\mathrm{ARCH}-\mathrm{LM}$ tests were less than $5 \%$, the null hypothesis stated that the ARCH effect is absent within the ALSI return series and can be rejected. Thus, it was concluded that heteroscedasticity was present within the ALSI return series, which supported the GARCH approach.

\subsection{Volatility dynamics}

Following Mandimika and Chinzara (2012), parameter estimates of the GARCH model were determined by the maximum likelihood (ML) method to investigate the volatility dynamics of the South African market. The four innovation distributions consisted of the standard normal (NORM), student- $\mathrm{t}$ (Std- $\mathrm{t})$, skewed student- $\mathrm{t}$

Table 1. Descriptive statistics of the ALSI returns

\begin{tabular}{l|c|c|c|c:c|c}
\hline Number of observations & Minimum & Maximum & Mean & Standard deviation & Skewness & Excess kurtosis \\
\hline 2498 & -0.037 & 0.042 & 0.000 & 0.010 & -0.167 & 1.277 \\
\hline
\end{tabular}

Table 2. Heteroscedasticity tests for the ALSI returns

\begin{tabular}{l|c|c}
\hline ALSI & LB $^{2}$ & ARCH-LM \\
\hline Returns & $567.920 * * *$ & $213.370 * * *$ \\
\hline
\end{tabular}

Note: $*, * * * * *$ mean the $\mathrm{p}$-value is significant at a $10 \%, 5 \%$ and $1 \%$ level of significance, respectively. 
(Skew- $\mathrm{t}$ ) and the Generalised Error Distribution (GED). The lag order for the GARCH (p, q) models were both set to one, as this was considered appropriate to capture volatility dynamics, based on information criteria. Table 3 showed the ML parameter estimates of the GARCH $(1,1)$ for different innovation distributions

Table 3. ML parameter estimates of the GARCH $(1,1)$ for different innovation distributions

\begin{tabular}{|c|c|c|c|c|}
\hline Estimates & NORM & Std- $t$ & Skew-t & GED \\
\hline$\hat{\mu}$ & - & $0.021^{* *}$ & - & $0.000 * * *$ \\
\hline$\hat{\alpha}_{1}$ & $0.057^{* * *}$ & $0.059 * * *$ & $0.060 * * *$ & $0.059 * * *$ \\
\hline$\widehat{\beta}_{1}$ & $0.942^{* * *}$ & $0.940 * * *$ & $0.939 * * *$ & $0.940 * * *$ \\
\hline$\hat{\alpha}_{1}+\widehat{\beta}_{1}$ & 0.999 & 0.999 & 0.999 & 0.999 \\
\hline AIC & -6.557 & -6.575 & -6.583 & -6.573 \\
\hline $\mathrm{BIC}$ & -6.552 & -6.565 & -6.574 & -6.564 \\
\hline JE & $34.524^{* * *}$ & $32.760 * * *$ & $34.694^{* * *}$ & $32.841^{* * *}$ \\
\hline
\end{tabular}

Note: $*, * *, * * *$ mean the $p$-value is significant at a $10 \%, 5 \%$ and $1 \%$ level of significance, respectively.

According to Table 3, the ARCH and GARCH effects were statistically substantial at the conventional 5\% level of significance. It was noteworthy that volatility was driven by the GARCH effect, which dominated the ARCH effect. This meant that long-term volatility was more persistent in the South African market than on a short-term basis. The sum of the ARCH and GARCH effects $\left(\widehat{\alpha}_{1}+\widehat{\beta}_{1}\right)$ was close but less than one. This meant that, firstly, the assumption of stationarity is detected, and secondly, the volatility present in the South African market could be further described.

According to Khan et al. (2016), if the assumption of stationarity is detected, this implied that the longrun mean variance converges to unconditional variance. If the unconditional variance for the innovation terms was less than one, as in this case, then the innovation terms were undefined and nonstationary. Consequently, the GARCH $(1,1)$ model could be seen as a regular linear ARMA model, which is limited in fitting higher moment properties, according to Brooks (2014). Secondly, the sum of the ARCH and GARCH effects was equal to 0.9 , confirming the presence and persistence of long-term volatility.

For the JE test, since the $p$-values were less than $5 \%$, the null hypothesis of asymmetry being ab- sent can be rejected. Since asymmetry was present and was inadequately captured by the GARCH (1, 1) model, this motivated the employment of the asymmetric GARCH models as showed in Tables 4, 5 and 6 . Given the asymmetric GARCH models were adequate for analysis by the significance of the ARCH and GARCH effects, the focus was placed on the asymmetry parameter $\hat{\gamma}$. Table 4 showed the ML parameter estimates of the GJRGARCH $(1,1)$ model with different innovation distributions.

Table 4. ML parameter estimates of GJR-GARCH for different innovation distributions

\begin{tabular}{l:c:c:c:c}
\hline Estimates & NORM & Std $-t$ & Skew $t$ & GED \\
\hline$\hat{\alpha}_{0}$ & - & - & - & - \\
\hdashline$\hat{\alpha}_{1}$ & $0.038^{* * *}$ & $0.0348^{* * *}$ & $0.038^{* * *}$ & $0.037^{* * *}$ \\
\hdashline$\hat{\beta}_{1}$ & $0.951^{* * *}$ & $0.952^{* * *}$ & $0.950^{* * *}$ & $0.951^{* * *}$ \\
\hdashline$\hat{\gamma}$ & $0.517^{* * *}$ & $0.603^{* * *}$ & $0.482^{* * *}$ & $0.546^{* * *}$ \\
\hdashline$\hat{\delta}$ & 2 & 2 & 2 & 2 \\
\hdashline$\hat{\alpha}_{1}+\hat{\beta}_{1}$ & 0.989 & 0.986 & 0.988 & 0.988 \\
\hdashline AIC & -6.581 & -6.595 & -6.602 & -6.592 \\
BIC & -6.574 & -6.586 & -6.590 & -6.583 \\
JE & $26.384^{* * *}$ & $25.920^{* * *}$ & $26.670^{* * *}$ & $26.219^{* * *}$ \\
\hline
\end{tabular}

Note: ${ }^{*}, * *, * * *$ mean the $\mathrm{p}$-value is significant at a $10 \%, 5 \%$ and $1 \%$ level of significance, respectively.

According to Table $4, \hat{\gamma}$ was statistically significant and positive for the GJR-GARCH model, which meant that the South African market showed the presence of asymmetric effects. The sign of $\hat{\alpha}_{1}$ indicated that positive volatility shocks have a greater impact on volatility, comparing to negative shocks of the same magnitude. Table 5 showed the ML parameter estimates of the EGARCH $(1,1)$ model with different innovation distributions.

Since the interpretation of $\hat{\gamma}$ for EGARCH followed the GJR model, the presence of asymmetric effects was confirmed. However, according to Table 5, the sign of $\hat{\alpha}_{1}$ was negative for EGARCH, where negative volatility shocks have a greater impact on volatility, comparing to positive shocks of the same magnitude. This was in contrast to GJR and suggested an inconsistency of the GARCH approach. Table 6 showed the ML parameter estimates of the APARCH $(1,1)$ model with different innovation distributions. 
Table 5. ML parameter estimates of EGARCH with different innovation distributions

\begin{tabular}{|c|c|c|c|c|}
\hline Estimates & NORM & Std- $t$ & Skew-t & GED \\
\hline$\hat{\alpha}_{0}$ & $-0.234^{* * *}$ & $-0.227 * * *$ & $-0.219 * * *$ & $-0.235^{* * *}$ \\
\hline$\hat{\alpha}_{1}$ & $-0.127 * * *$ & $-0.131^{* * *}$ & $-0.132^{* * *}$ & $-0.129 * * *$ \\
\hline$\hat{\beta}_{1}$ & $0.975^{* * *}$ & $0.976^{* * *}$ & $0.977^{* * *}$ & $0.975^{* * *}$ \\
\hline$\hat{\gamma}$ & $0.0780^{* * *}$ & $0.077^{* * *}$ & $0.074^{* * *}$ & $0.079 * * *$ \\
\hline$\widehat{\delta}$ & - & - & - & - \\
\hline$\widehat{\alpha}_{1}+\widehat{\beta}_{1}$ & 0.848 & 0.845 & 0.845 & 0.846 \\
\hline AIC & -6.618 & -6.624 & -6.637 & -6.623 \\
\hline $\mathrm{BIC}$ & -6.608 & -6.613 & -6.623 & -6.611 \\
\hline JE & $12.942 * * *$ & $12.739 * * *$ & $12.653^{* * *}$ & $12.788^{* * *}$ \\
\hline
\end{tabular}

Note: $*, * *, * * *$ mean the $\mathrm{p}$-value is significant at a $10 \%, 5 \%$ and $1 \%$ level of significance, respectively.

Table 6. ML parameter estimates of APARCH with different innovation distributions

\begin{tabular}{|c|c|c|c|c|}
\hline Estimates & NORM & Std- $t$ & Skew- $t$ & GED \\
\hline$\hat{\alpha}_{0}$ & - & $0.000^{* * *}$ & $0.000^{* * *}$ & $0.000^{* * *}$ \\
\hline$\hat{\alpha}_{1}$ & $0.060^{* * *}$ & $0.064^{* * *}$ & $0.064^{* * *}$ & $0.063^{* * *}$ \\
\hline$\hat{\beta}_{1}$ & $0.951^{* * *}$ & $0.926^{* * *}$ & $0.927^{* * *}$ & $0.926^{* * *}$ \\
\hline$\hat{\gamma}$ & $0.622^{* * *}$ & $1.000^{* * *}$ & $1.000^{* * *}$ & $1.000^{* * *}$ \\
\hline$\widehat{\delta}$ & 1 & 1 & 1 & 1 \\
\hline$\widehat{\alpha}_{1}+\widehat{\beta}_{1}$ & 1.011 & 0.990 & 0.991 & 0.989 \\
\hline AIC & -6.576 & -6.621 & -6.634 & -6.620 \\
\hline $\mathrm{BIC}$ & -6.569 & -6.610 & -6.620 & -6.608 \\
\hline JE & $26.153^{* * *}$ & $16.514^{* * *}$ & $16.801^{* * *}$ & $16.348^{* * *}$ \\
\hline
\end{tabular}

Note: $*, * *, * * *$ mean the $\mathrm{p}$-value is significant at a $10 \%, 5 \%$ and $1 \%$ level of significance, respectively.

According to Table 6, the APARCH for a normal innovation distribution was the only model that had a sum of the ARCH and GARCH effects being greater than one, in contrast to all the GARCH test results. Focusing on the interpretation of $\hat{\gamma}$ for the APARCH, the negative volatility shocks have a greater impact, comparing to positive shocks. This finding was in line with the EGARCH model but in contrast to the GJR model stated above. To settle this inconsistency, the optimal fitting GARCH model was determined by model diagnostics, after noting whether the models adequately captured the asymmetric nature of the ALSI returns.
According to Tables 4, 5 and 6, the JE test showed that asymmetry remained uncaptured by all three asymmetric GARCH models. Nonetheless, the optimal fitting GARCH model was the EGARCH followed by the APARCH, and the GJR. Concerning the probability distributions, the optimal fitting innovation distribution was Skew-t followed by Std-t, GED and NORM. Since the EGARCH was found to be the optimal model, the model's standardised innovations were further investigated.

\subsection{Uncaptured risk}

Following Mangani (2008), Mandimika \& Chinzara (2012), the standardized innovations of the EGARCH model were investigated to determine if the model adequately captured risks. Table 7 showed the preliminary test results for the innovations of the EGARCH $(1,1)$ model.

Table 7. Preliminary test results for the innovations of the EGARCH

\begin{tabular}{|c|c|c|}
\hline Test & Name & Results \\
\hline \multirow{3}{*}{ Normality } & SW & $0.993^{* * *}$ \\
\hline & $J B$ & $66.782^{* * *}$ \\
\hline & $A D$ & $4.118^{* * *}$ \\
\hline \multirow{2}{*}{ Heteroscedasticity } & $\mathrm{LB}^{2}$ & 19.084 \\
\hline & ARCH-LM & 19.062 \\
\hline \multirow{3}{*}{ Randomness } & Bartels rank & -0.095 \\
\hline & Cox-Stuart & 602.000 \\
\hline & BDS & 2.000 \\
\hline
\end{tabular}

Note: $*, * *, * * *$ mean the $\mathrm{p}$-value is significant at a $10 \%, 5 \%$ and $1 \%$ level of significance, respectively.

According to Table 7, since the $p$-values of the SW, JB and AD tests were all less than 5\%, the null hypothesis that the innovations are normally distributed can be rejected. For the $p$-values of both the $\mathrm{LB}^{2}$ and ARCH-LM tests, the null hypothesis that the ARCH effect is absent in the innovations cannot be rejected at a 5\% level of significance. Since the $p$-values of all three IID tests were greater than $5 \%$, the null hypothesis that the innovations are IID cannot be rejected. In conclusion, the absence of heteroscedasticity meant that the EGARCH adequately captured the volatile nature of the innovations. However, the model failed to capture asymmetry and nonnormality. 


\subsection{Risk-return relationship}

Given that both the GARCH-M models were adequate for analysis of the ARCH and GARCH effects, the focus was placed on the risk-premium parameter $\bar{\delta}$. Table 8 showed the results for the GARCH $(1,1)-M$ model with different innovation distributions.

Table 8. ML parameter estimates for GARCH-M with different innovation distributions

\begin{tabular}{|c|c|c|c|c|}
\hline $\begin{array}{c}\text { Parameter } \\
\text { estimates }\end{array}$ & NORM & Std- $t$ & Skew-t & GED \\
\hline$\widehat{\mu}$ & -0.000 & -0.000 & -0.000 & -0.000 \\
\hline$\hat{\alpha}_{1}$ & $0.059 * * *$ & $0.060 * * *$ & $0.062 * * *$ & $0.060 * * *$ \\
\hline$\widehat{\beta}_{1}$ & $0.940 * * *$ & $0.939 * * *$ & $0.937 * * *$ & $0.939 * * *$ \\
\hline$\widehat{\alpha}_{1}+\widehat{\beta}_{1}$ & 0.999 & 0.999 & 0.999 & 0.999 \\
\hline$\widehat{\delta}$ & $0.143^{*}$ & $0.133^{*}$ & 0.091 & $0.149 *$ \\
\hline AIC & -6.557 & -6.575 & -6.596 & -6.574 \\
\hline $\mathrm{BIC}$ & -6.548 & -6.564 & -6.580 & -6.562 \\
\hline $\mathrm{JE}$ & $32.808^{* * *}$ & $31.694^{* * *}$ & $32.772 * * *$ & $31.506 * * *$ \\
\hline
\end{tabular}

Note: $*, * *, * * *$ mean the $p$-value is significant at a $10 \%, 5 \%$ and $1 \%$ level of significance, respectively.

According to Table 8, the risk-premium parameter was statistically insignificant at a 5\% level of significance for all the innovation distributions. However, the risk premium was statistically significant at a $10 \%$ level of significance for the remaining three innovation distributions (NORM, Std-t and GED) except Skew-t. The latter finding was in contrast to the results of model testing, based on AIC and BIC, where the Skew-t innovation distribution was determined to be the optimal fitting distribution. Table 9 showed the results for the EGARCH $(1,1)$ $M$ model with different innovation distributions.

According to Table 9, all the risk-premium parameters were statistically substantial at a $5 \%$ level of significance for all the innovation distributions. This was in direct contrast to the GARCH-M model, particularly for the Skew-t innovation distribution. The EGARCH model is asymmetric, and Skew-t assumes that the innovations are asymmetric, implying a more robust combination in estimating the risk-return relationship. However, according to Table 8, the combination of the GARCH-M with Skew-t resulted in an in- significant risk-premium. Since EGARCH provided a more robust risk estimation, concerning the information criteria relative to the standard GARCH model, the overall EGARCH-M results were favoured.

Table 9. ML parameter estimates for EGARCH-M with different innovation distributions

\begin{tabular}{|c|c|c|c|c|}
\hline $\begin{array}{l}\text { Parameter } \\
\text { estimates }\end{array}$ & NORM & Std- $t$ & Skew- $t$ & GED \\
\hline$\widehat{\mu}$ & $-0.002 * * *$ & $0.002 * * *$ & $0.002 * * *$ & $-0.001^{* * *}$ \\
\hline$\hat{\alpha}_{0}$ & - & - & - & $-0.345^{* * *}$ \\
\hline$\widehat{\alpha}_{1}$ & $-0.119 * * *$ & $-0.119 * * *$ & $-0.126^{* * *}$ & $-0.127^{* * *}$ \\
\hline$\hat{\beta}_{1}$ & $1.000^{* * *}$ & $1.000 * * *$ & $1.000 * * *$ & $0.964^{* * *}$ \\
\hline$\widehat{\alpha}_{1}+\widehat{\beta}_{1}$ & 0.880 & 0.881 & 0.874 & 0.836 \\
\hline$\widehat{\delta}$ & $-0.242 * * *$ & $-0.206 * * *$ & $-0.204^{* * *}$ & $0.184^{* * *}$ \\
\hline$\hat{\gamma}$ & $0.063^{* * *}$ & $0.060 * * *$ & $0.062 * * *$ & $0.080 * * *$ \\
\hline AIC & -6.603 & -6.610 & -6.624 & -6.623 \\
\hline $\mathrm{BIC}$ & -6.591 & -6.596 & -6.608 & -6.607 \\
\hline JE & $15.681^{* * *}$ & $16.006^{* * *}$ & $15.875^{* * *}$ & $12.796 * * *$ \\
\hline
\end{tabular}

Note: $*, * *, * * *$ mean the $\mathrm{p}$-value is significant at a $10 \%, 5 \%$ and $1 \%$ level of significance, respectively.

With respect to the innovation distributions, according to AIC and BIC for the GARCH-M and EGARCH-M model, the optimal innovation distribution was Skew-t followed by Std-t, GED and NORM - in line with the above results for the volatility dynamics. Although the Skew-t was the optimal fitting innovation distribution, the GARCH-M and EGARCH-M risk-premium result was in direct contrast, revealing an inconsistency in the GARCH approach. This is caused by the fact that the GARCH-M is symmetric in nature, while the EGARCH-M is asymmetric. To consolidate this theory, the JE test was analyzed. According to Tables 8 and 9, the JE test revealed that both the GARCH-M and EGARCH-M models inadequately captured ALSI returns, irrespective of whether the GARCH model was symmetric or asymmetric.

\section{DISCUSSION}

The preliminary tests investigated the distribution and nature of the ALSI returns in order to motivate the employment of the GARCH ap- 
proach. Since the ALSI return data was found to be stationary, asymmetric and volatile, this validated the employment of the GARCH approach, by Khan et al. (2016). The GARCH $(1,1)$ model investigated the nature of volatility in the South African market. It was concluded by the sum of the ARCH and GARCH effects being equal to 0.9, that long-term volatility was present and strongly persistent in the South African market. The high volatility levels would result in mispricing's in the market, hence, an opportunity for arbitrage for investors to capitalize on. Thus, attract investors that seek a higher return and boost investment levels in the South African economy.

According to Khan et al. (2016), since the unconditional variance for the innovation terms was less than one, as in this case for the majority of the GARCH models, then the innovation terms were undefined and nonstationary. Consequently, the standard and asymmetric GARCH models could be seen as a regular linear ARMA model, which is limited in fitting higher moment properties, according to Brooks (2014). This finding was supported by the JE test, which showed that asymmetry remained uncaptured, by all the GARCH type models.

The standard APARCH model was the only exception to the above interpretation and explanation, as the sum of the ARCH and GARCH effects was greater than one. According to Khan et al. (2016), the forecast of unconditional variance increases to infinity following the increase of observations. The GARCH type models, which are essentially parametric, have a set of parameters with respect to finite sample size. As a result, the model cannot make an appropriate forecast of an infinite number of observations, according to Brooks (2014) and Jin (2017).

In the context of the asymmetric GARCH models, the presence of the asymmetric effects was confirmed. However, there was an inconsistency with regards to which type of shock or news had a greater impact for the South African market. This inconsistency was settled by determining the optimal fitting GARCH model, which was the EGARCH followed by the APARCH and the GJR. The result of the EGARCH being foremost was in contrast to the standard GARCH $(1,1)$ by Mangani (2008), TARCH by Mandimika and Chinzrara (2012) and APARCH by Ilupeju (2016). Since EGARCH and APARCH were foremost to GJR, it was concluded that negative volatility shocks or bad news have a greater impact on the South African market. Therefore, a stronger potential risk-return relationship is possible, since volatility indefinitely increases following bad news, according to Khan et al. (2016), Mandimika and Chinzara (2012).

Concerning the probability distributions, the optimal fitting innovation distribution was Skew- $t$ followed by Std-t, GED and NORM. Since the normal innovation distribution was the least good fit, this meant that the fitting of a normal innovation distribution to volatile and asymmetric financial data is unrealistic, in line with Jensen and Maheu (2018). Since EGARCH was the optimal model, the standardised innovations were investigated to determine if the risk had been fully captured. It was found that EGARCH adequately captured the volatile nature of the innovations, in line with Mandimika \& Chinzara (2012), Ilupeju (2016). However, the model failed to capture asymmetry and nonnormality, in line with Mangani (2008), Ilupeju (2016), Feng \& Shi (2017). The risk-return relationship was investigated by the GARCH-M and EGARCH-M.

For GARCH-M, the risk-premium parameter was statistically unsubstantial at a $5 \%$ level of significance for all the innovation distributions, whereas for EGARCH-M all the risk-premium parameters were statistically substantial. This was because the GARCH $(1,1)$ was not designed to assess the asymmetry, hence it was misspecified, in line with Jin (2017). For GARCH-M, the risk-premium parameters were statistically substantial at a $10 \%$ level of significance for the remaining three innovation distributions except for Skew-t, despite the Skew-t innovation distribution being the optimal fitting distribution. This point highlighted the significance of innovation distribution choice, as it affected parameter estimation, in line with Mandimika \& Chinzara (2012).

The significant risk-premium of EGARCH-M was expected, according to Khan et al. (2016), Mandimika \& Chinzara (2012), since the nega- 
tive news were found to dominate the positive news in terms of the volatility by EGARCH and APARCH. Therefore, it was confirmed that the negative news leads to a positive risk-return relationship due to the indefinite increase in volatil- ity following bad news relative to positive news. Consequently, investors would be more likely to optimize their return by investing after a period of bad news than positive news in the South African market.

\section{CONCLUSION}

It was found that the South African market was subject to strong persistent levels of volatility, which over a long period can be considered undesirable, as it can result in severe market instability. This can pose a challenge to policymakers and can be avoided by export diversification and the maintenance of macroeconomic and political regulatory frameworks. However, a fair amount of volatility can attract investors to seek a superior return, which exists in the South African market, since a positive risk-return relationship has been found. This finding was in contrast to previous South African studies, which found no risk-return relationship and can be explained by the limitations of the conventional GARCH approach, as stated by this study.

Investigating the volatility dynamics, several inconsistencies arose from the GARCH test results due to asymmetry being uncaptured by the model itself, in addition to the model's innovations, as was shown by all the JE tests and the standardised innovations of the EGARCH model. In the context of the risk-return relationship, contrasting results were found by the GARCH-M and EGARCH-M, with respect to the skewed student-t distribution. Thus, the choice of innovation distribution needs to be carefully taken into consideration. It was found that such a choice has a significant impact on parameter estimation. Since the choice of innovation distribution can aid with capturing the asymmetry that the model itself cannot account for, this study recommends the exploration of different nonnormal innovation distributions to improve the accuracy of the GARCH test results, as an area for future research.

\section{AUTHOR CONTRIBUTIONS}

Conceptualization: Nitesha Dwarika, Peter Moores-Pitt.

Data curation: Nitesha Dwarika, Retius Chifurira.

Formal analysis: Nitesha Dwarika, Peter Moores-Pitt.

Investigation: Nitesha Dwarika.

Methodology: Nitesha Dwarika, Retius Chifurira.

Project administration: Peter Moores-Pitt.

Software: Nitesha Dwarika.

Supervision: Peter Moores-Pitt, Retius Chifurira.

Validation: Nitesha Dwarika, Peter Moores-Pitt, Retius Chifurira.

Visualization: Nitesha Dwarika, Peter Moores-Pitt, Retius Chifurira.

Writing - original draft: Nitesha Dwarika.

Writing - review \& editing: Nitesha Dwarika, Peter Moores-Pitt, Retius Chifurira.

\section{REFERENCES}

1. Adu, G., Alagidede, P., \& Karimu, A. (2015). Stock return distribution in the BRICS. Review of Development Finance, 5(2), 98-109. https://doi.org/10.1016/j. rdf.2015.09.002

2. Bollerslev, T. (1986). Generalized autoregressive conditional heteroskedasticity. Journal of

Econometrics, 31, 307-327. https://doi.org/10.1016/03044076(86)90063-1

3. Brooks, C. (2014). Introductory Econometrics for Finance. New York: Cambridge University Press.
4. Ding, X., Granger, C. W. J., \& Engle, R. F. (1993). A long memory property of stock market returns and a new model. Journal of Empirical Finance, 1, 83-106. https://doi.org/10.1016/09275398(93)90006-D 
5. Engle, F. R. (1982). Autoregressive Conditional Heteroskedasticity with Estimates of the Variance of United Kingdom Inflation. Econometrica, 50(4), 987-1007. https://doi.org/10.2307/1912773

6. Engle, R. F., Lilien, D., \& Robins, R. (1987). Estimating time varying risk premia in the term structure: the ARCH-M model. Econometrica, 55, 391-407. https:// doi.org/10.2307/1913242

7. Feng, L., \& Shi, Y. (2017) A simulation study on the distributions of disturbances in the GARCH model. Cogent Economics and Finance, 5(1), 1-19. https://doi.org/10.1080/23322039. 2017.1355503

8. Glosten, L. R., Jagannathan, R., \& Runkle, D. E. (1993). On the Relation between the Expected Value and the Volatility of the Nominal Excess Return on Stocks. The Journal of Finance, 48(5), 1779-1801. https://doi. org/10.1111/j.1540-6261.1993. tb05128.x

9. Ilupeju, Y. E. (2016). Modelling South Africa's market risk using the APARCH model and heavy-tailed distributions. (Master's thesis). University of KwaZulu-Natal. Durban. South Africa. Retrieved from https://researchspace.ukzn. ac.za/handle/10413/15574
10. Jensen, M. J., \& Maheu, J. M. (2018). Risk, Return and Volatility Feedback: A Bayesian Nonparametric Analysis. Journal of Risk and Financial Management, 11(52), 1-29. Retrieved from https://ideas.repec.org/a/gam/jjrfmx/v11y2018i3p52-d167993.html

11. JIN, X. (2017). Time-varying return-volatility relation in international stock markets. International Review of Economics and Finance, 51, 157-173. https:// doi.org/10.1016/j.iref.2017.05.015

12. Khan, F., Rehman, S., Khan, H., \& Xu, T. (2016). Pricing of risk and volatility dynamics on an emerging stock market: evidence from both aggregate and disaggregate data. Economic Research-Ekonomska Istrazivanja, 29(1), 799-815. https://doi.org/10. 1080/1331677X.2016.1197554

13. Mandimika N. Z., \& Chinzara, Z. (2012). Risk-return trade-off and behaviour of volatility on the South African stock market: evidence from both aggregate and disaggregate data. South African Journal of Economics, 80(3), 345-365. Retrieved from https://www.researchgate.net/ publication/264508151_Riskreturn_trade-off_and_behaviour_ of_volatility_on_the_south_african_stock_market_Evidence from_both_aggregate_and_disaggregate_data
14. Mangani R. (2008). Modelling return volatility on the JSE Securities Exchange of South Africa. African Finance Journal, 10(1), 55-71. Retrieved from https://www.researchgate.net/publication/46568121_Modelling_Return_Volatility_on_the_JSE_Securities_Exchange_of_South_Africa

15. Nelson, D. B. (1991). Conditional heteroskedasticity in asset returns: A new approach. Econometrica, 59, 347-370. https://doi. org/10.2307/2938260

16. Park, S.Y., Ryu, D., \& Song, J. (2017). The dynamic conditional relationship between stock market returns and implied volatility. Physica A, 482, 638648. https://doi.org/10.1016/j. physa.2017.04.023

17. Spierdijk, L. (2016). Confidence intervals for ARMA-GARCH Value-at-Risk: The case of heavy tails and skewness. Computational Statistics and Data Analysis, 100 545-559. https://doi.org/10.1016/j. csda.2014.08.011

18. Yu, J. H., Kang, J., \& Park, S. (2019). Information availability and return volatility in the bitcoin Market: Analysing differences of user opinion and interest. Information Processing and Management, 56, 721-732. https:// doi.org/10.1016/j.ipm.2018.12.002 